\title{
Removal of Ni (II) from Aqueous Solution by Adsorption onto Activated Carbon Prepared from Lapsi (Choerospondias axillaris) Seed Stone
}

\author{
Rajeshwar M. Shrestha ${ }^{a *}$, Margit Varga ${ }^{b}$, Imre Varga $^{\mathrm{b}}$ Amar P. Yadav $^{\mathrm{c}}$, \\ Bhadra P. Pokharel ${ }^{a}$, Raja Ram Pradhananga ${ }^{c}$ \\ ${ }^{a}$ Department of Engineering Science and Humanities, Institute of Engineering, Central Campus, Pulchowk, \\ Tribhuvan University, Nepal \\ ${ }^{b}$ Department of Analytical Chemistry, Eotvos Lorand University, Budapest, Hungary \\ ${ }^{c}$ Central Department of Chemistry, Tribhuvan University, Nepal \\ Corresponding Email: r_shrestha4444@hotmail.com
}

\begin{abstract}
Activated carbons were prepared from Lapsi seed stone by the treatment with $\mathrm{H}_{2} \mathrm{SO}_{4}$ and $\mathrm{HNO}_{3}$ for the removal of $\mathrm{Ni}$ (II) ions from aqueous solution. Two activated carbon have been prepared from Lapsi seed stones by treating with conc. $\mathrm{H}_{2} \mathrm{SO}_{4}$ and a mixture of $\mathrm{H}_{2} \mathrm{SO}_{4}$ and $\mathrm{HNO}_{3}$ in the ratio of $1: 1$ by weight for removal of $\mathrm{Ni}$ (II) ions. Chemical characterization of the resultant activated carbons was studied by Fourier Transform Infrared Spectroscopy and Boehm titration which revealed the presence of oxygen containing surface functional groups like carboxyl, lactones and phenols in the carbons. The optimum $\mathrm{pH}$ for nickel adsorption is found to be 5. The adsorption data were better fitted with the Langmuir equations than Freundlich adsorption equation to describe the equilibrium isotherms. The maximum adsorption capacity of $\mathrm{Ni}$ (II) on the resultant activated carbons was $28.25 .8 \mathrm{mg} \mathrm{g}^{-1}$ with $\mathrm{H}_{2} \mathrm{SO}_{4}$ and $69.49 \mathrm{mg} \mathrm{g}^{-1}$ with a mixture of $\mathrm{H}_{2} \mathrm{SO}_{4}$ and $\mathrm{HNO}_{3}$. The waste material used in the preparation of the activated carbons is inexpensive and readily available. Hence the carbons prepared from Lapsi seed stones can act as potential low cost adsorbents for the removal of $\mathrm{Ni}$ (II) from water.
\end{abstract}

Keywords: Adsorption, Lapsi seed stones, Carbon, Adsorption isotherms, Nickel

\section{Introduction}

Heavy metals like lead, cadmium, nickel, chromium etc even at lower concentrations are hazardous to the environment due to toxicity and non-biodegradability [1]. Among heavy metals, nickel is one of the most utilized in the manufacturing process of stainless steel, super alloys, metallic alloys, coins, batteries etc. Direct exposition to nickel causes dermatitis. Some nickel compounds, as carbonyl, are carcinogenic and easily absorbed by skin [2]. Acute poisoning of $\mathrm{Ni}$ (II) causes headache, dizziness, nausea and vomiting, chest pain, tightness of the chest, dry cough and shortness of breath, rapid respiration, cyanosis and extreme weakness [3]. The removal of such a heavy metal from contaminated water bodies has been attempted by several scientists employing a wide variety of techniques including chemical precipitation, chemical oxidation or reduction, filtration, ion exchange, electrochemical treatment, membrane filtration, reverse osmosis and adsorption. However, most of these methods have considerable disadvantages including incomplete metal removal, high capital, operational cost and the disposal of residual metal sludge which are not suitable for small scale industries [4].

Adsorption process has been used exclusively in water treatment and many studies have been carried out to find inexpensive and chemico-physically feasible adsorbent. Many reports have appeared on the development of low cost activated carbon from cheaper and readily available 
materials. Activated carbons with their high surface area, micro porous character and chemical nature of their surface have made them potential adsorbents for the removal of heavy metals from water.Caboxylic lactonic, phenolic, and other organic functional groups are located at the edges of hexagonal layer planes and are responsible for surface reactivity of activated carbon. Ionization of these functional groups in solution is $\mathrm{pH}$ dependent and leads to a buildup of a charged interface between the solid surface and the bulk of the solution [4].

There are a quite large number of studies regarding the preparation of activated carbons from agriculture wastes, fruit stones, hard shell of fruit stones. bagasse, manure compost, oil palm waste, agriculture residue from sugarcane, saw dust, Rosa canina sp. Seeds, sewage sludge [5] Most of activated carbons are prepared by a two stage process carbonization followed by activation. The first step is to enrich the carbon content and to create an initial porosity and activation process helps in enhancing the pore structure. The activation can be carried by two different processes physical and chemical. Chemical activation has two important advantages as compared to physical activation. One is lower temperature in which the process is accomplished. The other is that the global yield to the chemical activation tends to be greater since burn off char is not required [6]. Among the numerous dehydrating agents, sulphuric acid is the widely used chemical agent in the preparation of activated carbon.

Lapsi seed stone is the waste product of Lapsi fruits. (Lapsi) Choreospondias axillaris belongs to the family Anacardiaceous. It is a large, fruit bearing deciduous tree native to the hills of Nepal (865-1900m). Lapsi fruit is consumed fresh, pickled or processed into a variety of sweet and sour fruit products locally called "Mada" or"Titaura". It is a rich source of vitamin C. It is also believed to aid in digestion and is often consumed after a protein rich meal. Seed stones are used as fuel in brick kilns in the factories and the trunk of the tree is used as fuel wood and timber $[7,8]$.

In this study, activated carbon developed from Lapsi seed stones have been used for the removal of $\mathrm{Ni}$ (II) ions from aqueous solution since the stones are readily available and can be used as a viable adsorbent for the removal of heavy metals. The effects of initial adsorbate concentration and $\mathrm{pH}$ on the removal of $\mathrm{Ni}(\mathrm{II})$ have been studied.

\section{Materials and Methods}

\subsection{Preparation of Adsorbents}

Lapsi seeds were first washed with tap water then with distilled water and dried in an oven at $110^{\circ} \mathrm{C}$ for 12 hours. The dried seeds were crushed into small particles by Jaw Crusher. The Lapsi seed particles were divided into two parts. One part of the Lapsi seed particles were treated with concentrated $\mathrm{H}_{2} \mathrm{SO}_{4}$ in 1:1 weight ratio and kept in an oven maintained at a temperature of $150^{\circ} \mathrm{C}$ for 24 hours [9]. The particles were then washed with distilled water till the $\mathrm{pH}$ and conductivity of the washing were equal to that of distilled water. The particles were dried in an oven at $110^{\circ} \mathrm{C}$ for 10 hours. The particles were then ground and sieved to get the particles size of $100 \mu \mathrm{m}$. The carbon has been named as Carbon -1.

Another part of the Lapsi seed particles were treated with concentrated $\mathrm{H}_{2} \mathrm{SO}_{4}$ in 1:1 weight ratio The mixture was then treated with conc. $\mathrm{HNO}_{3}$ for further oxidation and was kept in an oven at $130^{\circ} \mathrm{C}$ for 24 hours. The dried mixture was washed with distilled water till the $\mathrm{pH}$ and 
conductivity of the washing were equal to that of distilled water. The acid free sample was dried, ground and then sieved to the particle size of $100 \mu \mathrm{m}$. The carbon has been named as Carbon-2.

\subsection{Characterization of the activated Carbon}

The adsorbents were studied by FTIR study and Boehm titration. The Fourier transform infrared (FTIR) spectra were recorded on a Perkin-Elmer Model 1605 FT-IR spectrometer .Oxygen containing functional groups present on the activated carbons prepared were determined qualitatively by the FTIR spectroscopy. Quantification of the functional groups was determined by Boehm titration.

\subsection{Chemicals}

All chemicals and reagents used were of analytical grade. Stock solutions of Ni (II) were prepared from nickel sulphate in deionized water. Digital $\mathrm{pH}$ meter was used to measure the $\mathrm{pH}$ values of the solutions. Solutions of $0.1 \mathrm{M} \mathrm{NaOH}$ and $0.1 \mathrm{HCl}$ were used for $\mathrm{pH}$ adjustment. All the working solutions were prepared by diluting the stock solutions with deionized water.

\subsection{Adsorption studies}

Batch adsorption experiments were carried out in a series of stoppered reagent bottles. A weighed amount $(0.05 \mathrm{~g})$ of adsorbent was introduced into the reagent bottles $(50 \mathrm{ml})$ containing various concentration of nickel. The total volume of the aqueous solution is equal to $25 \mathrm{ml}$.The solution $\mathrm{pH}$ was adjusted to the desired value by adding $0.1 \mathrm{M} \mathrm{HCl}$ and $0.1 \mathrm{M} \mathrm{NaOH}$. The bottles were then shaken at room temperature $\left(25 \pm 2{ }^{\circ} \mathrm{C}\right)$ using an electric shaker for a prescribed time to attain the equilibrium.

The solutions were filtered and final Nickel (II) concentrations of metal ions were determined by using an atomic absorption spectrophotometer with hallow cathode lamp and air acetylene flame.

The instrument calibration was checked by using standard metal solutions. The amount of Nickel (II) adsorbed was calculated by the following mass balance equation.

$$
\mathrm{Ce}=\frac{(\mathrm{Co}-\mathrm{Ce}) * \mathrm{~V}}{\mathrm{~W}}
$$

Where $\mathrm{C}_{\mathbf{0}}$ and $\mathrm{C}_{\mathrm{e}}$ are initial and equilibrium concentration of metal ion $(\mathrm{mg} / \mathrm{L})$ respectively, $\mathrm{m}$ is the mass of adsorbent in gram $(\mathrm{g})$ and $\mathrm{V}$ was the volume of the solution in liter $(\mathrm{L})$.

\section{Results and discussions}

\subsection{FTIR}

FTIR study confirmed the presence of oxygenated functional groups in C-1 and C-2. The FTIR spectrum of the C-1 and C -2 is shown in Fig. 1. The bands at about $1604 \mathrm{~cm}^{-1}$ and $1720 \mathrm{~cm}^{-1}$ are attributed to $v(\mathrm{C} \mathrm{O})$ vibrations in the carboxyl groups. The bands at about $1300-1365 \mathrm{~cm}^{-1}$ are attributed to $v(\mathrm{O}-\mathrm{H})$ vibrations in the hydroxyl and phenolic groups. The appearance of bands between 900 and $1300 \mathrm{~cm}^{-1}$ could be assigned to $\mathrm{C}-\mathrm{O}$ stretching vibrations. It is obvious that the main oxygen groups present in the carbon- 1 and carbon -2 are lactones, carboxyl and phenolic groups [10]. 


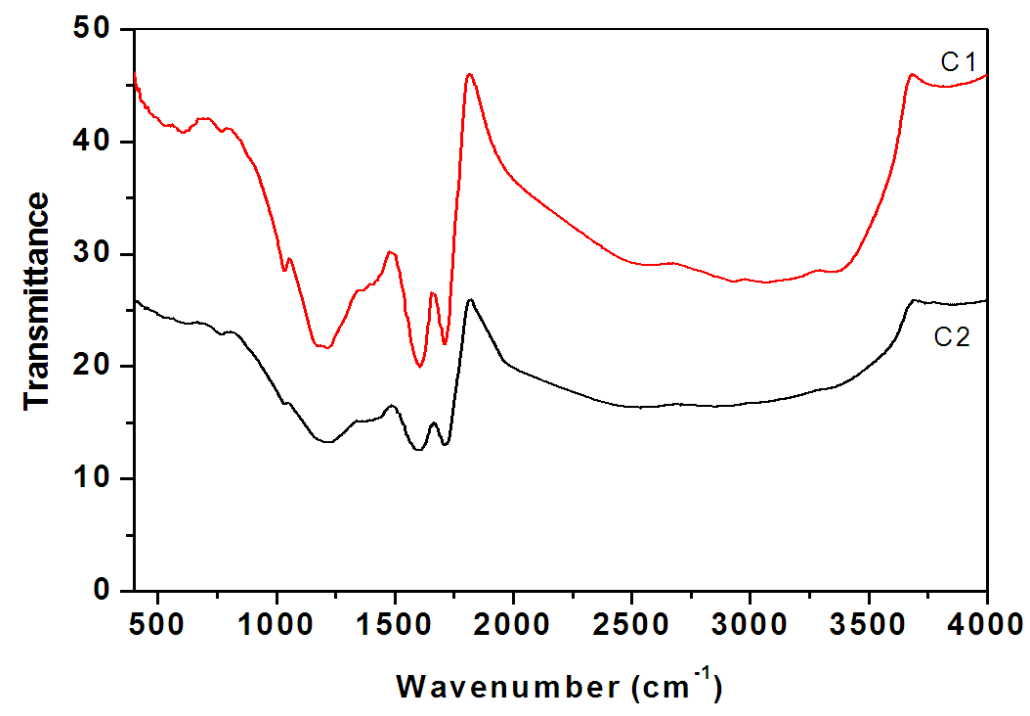

Figure 1: FTIR Study of Carbon-1 and Carbon-2

\subsection{Boehm Titration}

The quantification of surface oxygen functional groups in C-1 and C-2 was measured by Boehm titration method [11, 12]. The method based on that the weakest base $\mathrm{NaHCO}_{3}$ neutralizes only the strongest acidic carbon surface functionalities which are carboxyl groups, while $\mathrm{Na}_{2} \mathrm{CO}_{3}$ neutralizes carboxylic and lactonic groups. The strongest base $\mathrm{NaOH}$ neutralizes carboxylic, lactonic and phenolic groups. On the basis of amount of acid and bases consumed the different kinds of functional groups can be quantitatively calculated. Table 1 shows the mill equivalent of carboxylic, phenolic and lactonic groups present per gram of activated carbon. The large quantities of the acidic functional groups on the surface of C-1 and C-2 make them high cation exchange capacity and benefit for the $\mathrm{Ni}$ (II) ions adsorption [13].

Table 1: Boehm titration result of Carbon -1 and Carbon -2

\begin{tabular}{|l|c|c|c|}
\hline \multirow{2}{*}{ Adsorbents } & \multicolumn{3}{|c|}{ Functional groups in mill equivalent per gram (meq/g) } \\
\hline & Carboxyl & Phenol & Lactones \\
\hline Carbon-1 & 0.75 & 0.62 & 0.5 \\
\hline Carbon-2 & 1.25 & 0.75 & 0.6 \\
\hline
\end{tabular}

\subsection{Effect of pH}

The $\mathrm{pH}$ of the solution has a significant impact on the uptake of heavy metal ions since it determines the surface charge of the adsorbent, the degree of ionization and speciation of the adsorbate.

The effect of $\mathrm{pH}$ on the adsorption of $\mathrm{Ni}$ (II) on activated carbons developed from Lapsi seeds has been studied by varying $\mathrm{pH}$ from 2-6 as shown in Fig 2 and 3. It has been shown in the 
figure that the uptake of $\mathrm{Ni}$ depends on $\mathrm{pH}$, it increases with the increase in $\mathrm{pH}$ and reaching maximum adsorption of $\mathrm{Ni}$ around $\mathrm{pH} 6$. The continued increase in adsorptive capacities of $\mathrm{Ni}$ with increase in $\mathrm{pH}$ is due to the decrease in hydrogen ion concentration as $\mathrm{pH}$ value increases. At lower $\mathrm{pH}$ higher concentration of $\mathrm{H}^{+}$ions present in aqueous medium will compete with the positively charged $\mathrm{M}^{2+}$ ion for the surface adsorbing sites thereby leading to a decrease in the removal of metal ions [14]. In other words under acidic condition solutions both adsorbent and metal ions are positively charged $\left(\mathrm{M}^{2+}\right.$ and $\left.\mathrm{H}^{+}\right)$and hence their interaction is via electrostatic interaction. The final $\mathrm{pH}$ values at equilibrium after adsorption were lower than the initial $\mathrm{pH}$ value, indicating that the $\mathrm{Ni}$ ions are adsorbed and hydrogen ions are released from the adsorbent. This is also confirmed by the result that the increase of acidic surface groups favored the adsorption process. The effect of $\mathrm{pH}$ on $\mathrm{Ni}$ (II) adsorption onto two carbons was studied over a $\mathrm{pH}$ range $2-6$ at $25^{\circ} \mathrm{C}$ in order to avoid metal hydroxides.

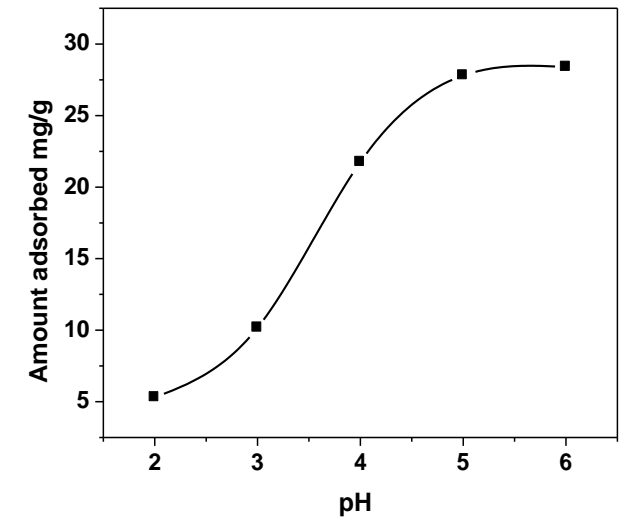

Figure 2: Effect of $\mathrm{pH}$ on the adsorption on $\mathrm{Ni}$ on $\mathrm{C}-1$

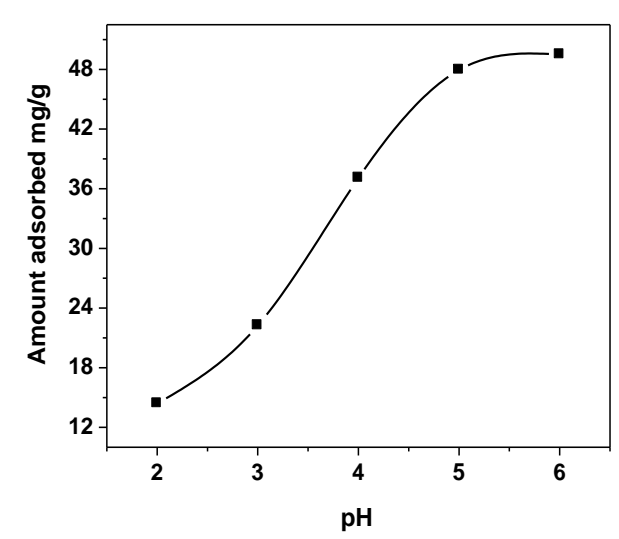

Figure 3: Effect of $\mathrm{pH}$ on the adsorption on $\mathrm{Ni}$ on $\mathrm{C}-2$

\subsection{Effect of metal ion concentration}

In batch adsorption processes the initial metal ion concentration of metal ions in solution plays an important role as driving force to overcome the mass transfer resistance between the solution and solid phase. So the removal efficiency of $\mathrm{Ni}$ ions by activated carbon derived from Lapsi seed stones initially increased with increasing metal ions concentration as shown in Fig. 4. At initial stage there were large number of binding sites available for adsorption i.e. the number of nickel ions which are available in the solution is less as compared to the available sites on the adsorbents and the metal ions in solution would interact the binding sites and thus facilitated more adsorption where as in higher concentrations the metal ions get left unabsorbed in the solution due to saturation of the binding sites [15] 


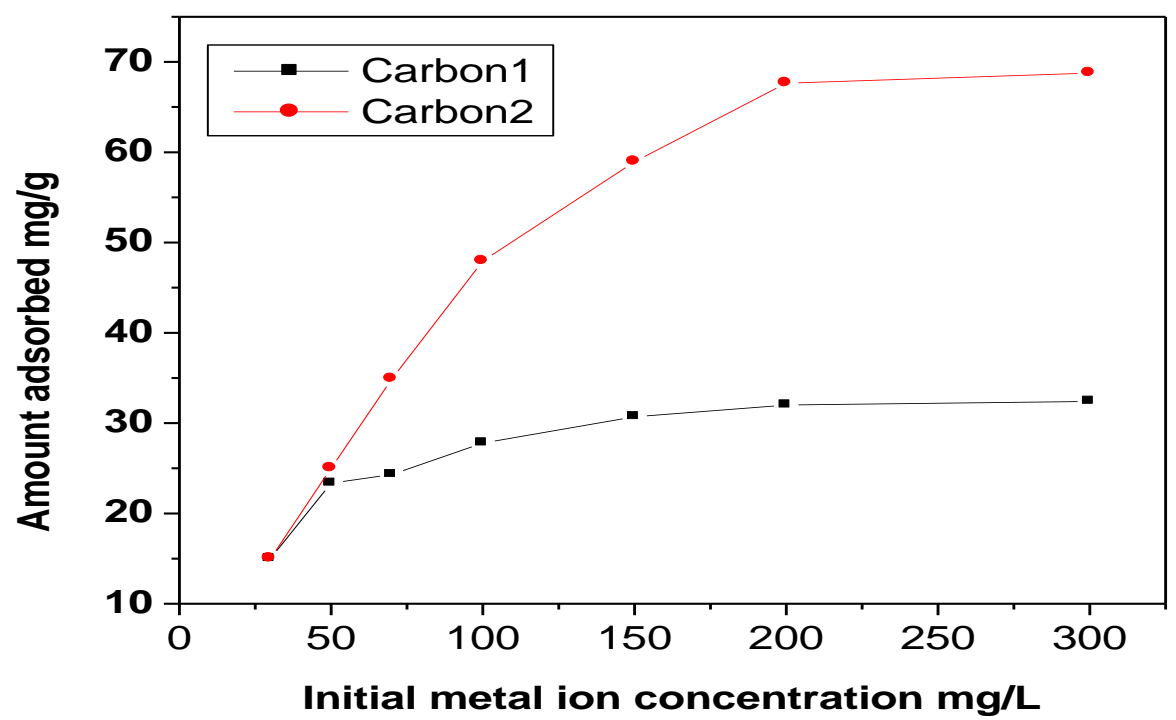

Figure 4: Effect of initial metal ion concentration for adsorption of $\mathrm{Ni}$ on $\mathrm{C}-1$ and $\mathrm{C}-2$

\subsection{Adsorption isotherm}

Adsorption isotherm indicates how molecules of adsorbate distribute between the solid and liquid phase when the adsorption process reaches an equilibrium state [16]. Several models have been used in the literature to describe the experimental data of adsorption isotherms. Langmuir and Freundlich models are most frequently employed models. In this work both the models were used to describe the relation between the amount of $\mathrm{Ni}(\mathrm{II})$ ions adsorbed and its equilibrium concentration in solution. Langmuir adsorption isotherm assumes that the adsorption occurs in a monolayer , or the adsorption may only occur at a fixed number of localized siteson a surface on which all the adsorption sites are identical and energetically equilivalent.

The linear form of Langmuir isotherm equation is given as

$$
\frac{\mathrm{Ce}}{\mathrm{qe}}=\frac{1}{\mathrm{qmb}}+\frac{1}{\mathrm{qm}} \mathrm{C}
$$

Where $\mathrm{q}_{\mathrm{e}}$ is the amount of Nickel ions adsorbed $\left(\mathrm{mg} \mathrm{g}^{-1}\right)$ and Ce is the equilibrium concentration of nickel ions in the bulk solution ( $\mathrm{mg} \mathrm{L}^{-1}$ ) while $\mathrm{q}_{\mathrm{m}}$ is the monolayer adsorption capacity (mg $\mathrm{g}^{-1}$ ) and $\mathrm{b}$ is the Langmuir constant[17]. Langmuir constant and adsorption capacity are determined from the slope and intercept of the plot Ce/qe versus $\mathrm{Ce}$ and are presented in Table.2. 


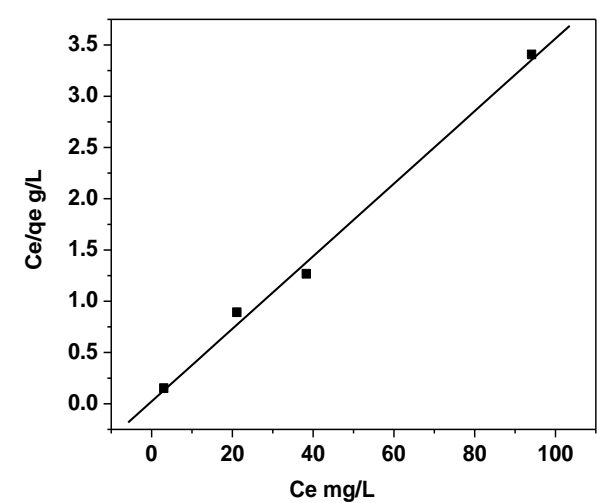

Figure 5: Langmuir isotherm for adsorption of $\mathrm{Ni}(\mathrm{II})$ on $\mathrm{C}-1$

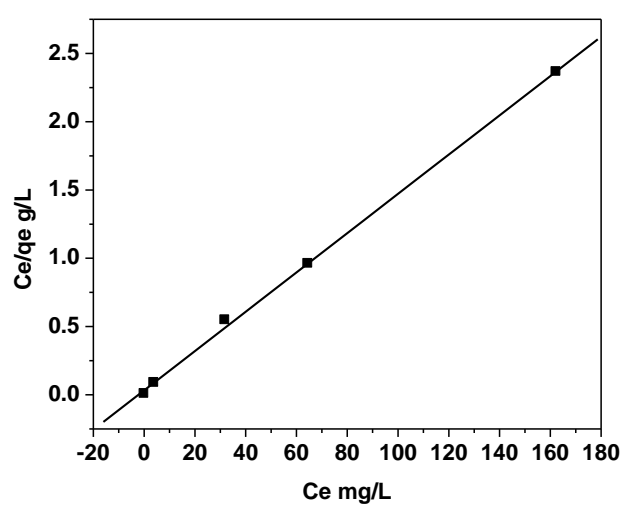

Figure 6: Langmuir isotherm for adsorption of $\mathrm{Ni}(\mathrm{II})$ on $\mathrm{C}-2$

Freundlich isotherm is an empirical equation describing the heterogeneous adsorption and assumes that different sites with several adsorption energies are involved .The linear form of the Freundlich equation is represented as follows.

$$
\log \mathrm{qe}=\log \mathrm{K}+\frac{1}{\mathrm{n}}+\log \mathrm{Ce}
$$

Where $\mathrm{K}$ and $\mathrm{n}$ areFreundlich constants related to adsorption capacity and adsorption intensity respectively. From the slope and intercept of straight portion of the linear plot obtained by plotting $\log$ qe versus $\log \mathrm{Ce}$, the values of Freundlich parameters are calculated [18].

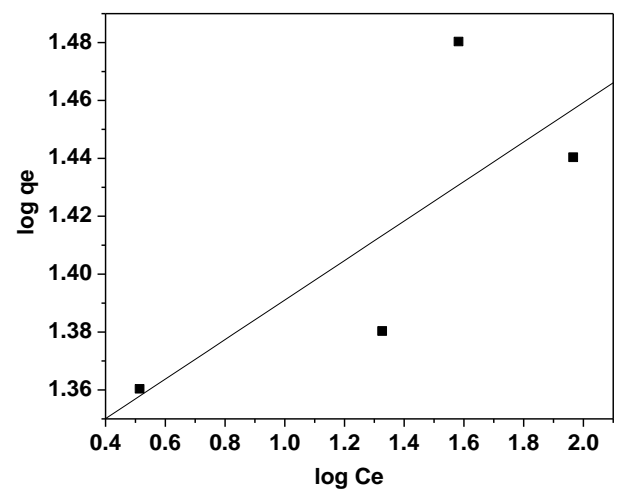

Figure 7: Freundlich isotherm for adsorption of $\mathrm{Ni}$ (II) on C-1

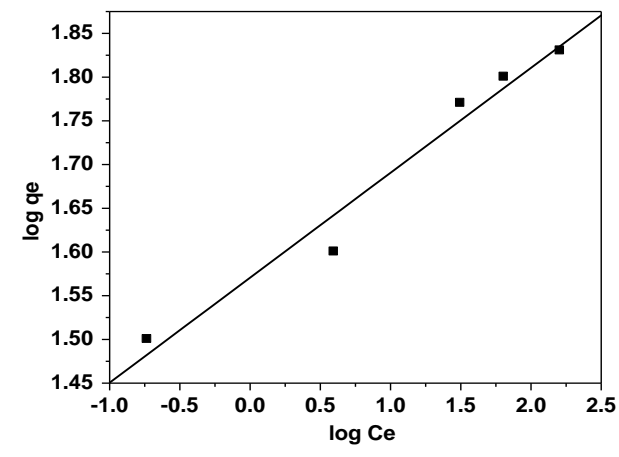

Figure 8: Freundlich isotherm for adsorption of $\mathrm{Ni}$ (II) on C-2

Langmuir and Freundlich constants are given in Table .2. Fig .5 and 6 show that the isotherm data better fits the Langmuir equation than Freundlich equation since the coefficient of determination values $\left(\mathrm{R}^{2}=0.994\right.$ and 0.998 for $\mathrm{C}-1$ and $\mathrm{C}-2$ respectively) are higher than that of Freundlich isotherms $\left(\mathrm{R}^{2}=0.579\right.$ and 0.966) Langmuir and Freundlich constants are given in Table 2.

Table 2: Langmuir and Freundlich constants for Nickel adsorption onto C-1 and C-2 at pH 5 


\begin{tabular}{|l|c|c|c|c|c|c|}
\hline \multicolumn{1}{|c|}{ Adsorbents } & \multicolumn{3}{|c|}{ Langmuir } & \multicolumn{3}{c|}{ Freundlich } \\
\hline & $\mathbf{b}$ & $\mathbf{q}_{\mathbf{m}}$ & $\mathbf{R}^{\mathbf{2}}$ & $\log \mathbf{K}$ & $\mathbf{1 / n}$ & $\mathbf{R}^{\mathbf{2}}$ \\
\hline Carbon-1 & 1.517 & 28.25 & 0.994 & 1.323 & 0.068 & 0.579 \\
\hline Carbon-2 & 0.438 & 69.49 & 0.998 & 1.57 & 0.120 & 0.966 \\
\hline
\end{tabular}

Table 3: Adsorption capacities of Nickel by various adsorbents

\begin{tabular}{|c|l|c|l|}
\hline S.No. & Adsorbents & $\begin{array}{c}\text { Adsorption } \\
\text { capacity } \\
\text { Qmax mg g-1 }\end{array}$ & References \\
\hline 1 & $\begin{array}{l}\text { Nanocrystalline } \\
\text { Calcium hydroxypatite }\end{array}$ & 46.17 & E.Salahi et al ,2010 \\
\hline 2 & Activated carbon fromLotus stalk & 31.45 & LiHui Huang et al 2011 \\
\hline 3 & AC from Bacillus thuringiensis & 45.87 & Ayaten Oztruck et al 2007 \\
\hline 4 & Carbon -1 & 28.25 & This study \\
\hline 5 & Carbon-2 & 69.49 & This study \\
\hline
\end{tabular}

Carbon -2 shows more adsorptive power than Carbon-1 since Carbon- 2 has more surface functional group than Carbon-1.The activated carbon-2 prepared from Lapsi Seed Stone is better in adsorption of $\mathrm{Ni}(\mathrm{II})$ than the adsorbents prepared from Lotus stalk, and Bacillus thuringiensis.

\section{Conclusion}

The activated carbons prepared from Lapsi seed stones are effective adsorbents for the removal of Nickel (II) from aqueous solutions. The optimum $\mathrm{pH}$ for nickel adsorption is found to be 5 . Experimental results are in good agreement with Langmuir adsorption isotherm model, and have shown a better fitting to the experimental data. Boehm titration showed that there is a large quantity of functional groups such as carboxyl, phenolic and lactonic groups existed on the surface of $\mathrm{C}-1$ and $\mathrm{C}-2$.Batch adsorption experiment showed that $\mathrm{Ni}$ (II) ion adsorption properties are dependent on $\mathrm{pH}$ and metal ion concentration. The optimum $\mathrm{pH}$ for the uptake of lead adsorption on the adsorbents is 5 . The carbon prepared by chemical activation with a mixture of $\mathrm{H}_{2} \mathrm{SO}_{4}$ and $\mathrm{HNO}_{3}$ showed more adsorptive capacity than that of the carbon prepared by treatment with $\mathrm{H}_{2} \mathrm{SO}_{4}$.

\section{References}

[1] Mohammad, M., Maitra, S., Ahmad, N., Bustam, A., Sen, T. K., and Dutta B. K. (2010). Metal ion removal from aqueous solutions physic seed hull, Journal of Hazardous Materials, 170, 263-272.

[2] Vieira, M.G. A., Almeida, A. F., Neto, M., Gimenes, L., M.G., and da Silva, C. (2010). Removal of nickel on Bofe bentonite calcined clay in porous bed, Journal of Hazardous Materials, 176, 109-118.

[3] Malkoc, E., and Nuhoglu, Y. (2005). Investigation of Nickel (II) from aqueous solutions using tea factory waste, Journal of Hazardous Materials, B127, 120-128. 
[4] Karthika, C., Venilamani, N., Pattabhi, S., and Sekar, M. (2010). Utilization of Sago waste as an adsorbent for the removal of heavy metals from aqueous solution Kinetics, Isotherm studies, International Journal of Engineering Science and Technology, 2 (6), 1867-1879.

[5] Hui, L., Yuan, H., Sung, Y., Yang, T., Li, L. (2011). Adsorption behavior of Ni (II) on lotus stalks derived active carbon by phosphoric acid activation, Desalination, 268, $12-19$.

[6] Mohammadi, S. Z., Karimi, M. A., Afzali, D., and Mansouri, F. (2010). Removal of Pb (II) ions from aqueous Solution using activated carbon from Sea buckthorn by chemical activation, Desalination, 263, 83-93.

[7] Mouni, L., Merabet, D., Bouzaza, A., and Belkhiri, L. (2011). Adsorption of Pb (II) from aqueous solutions using activated carbon developed from Apricot stone, Desalination, 276, 148-153.

[8] Prajapati, S., Sharma, S., and Agrawal, V. P. (2009). Characterization of Choerospondias axillaris (Lapsi) fruit protease, International Journal of Life Sciences, 3, 24-31.

[9] Poudel, K. C. (2003). Domesticating Lapsi (Choerospondias axillaris) for fruit production in middle mountain agroforestry systems in Nepal, Himalayan Journal of Sciences, 1(1), 55-58.

[10] Gupta, S., and Babu, B.V. (2009). Utilization of waste product (tamarind seeds) for the removal of Cr (VI) from aqueous Solutions: Equilibrium, kinectics and regeneration studies, Journal of Environmental Management, 90, 3013-3022.

[11] Acharya, K., Sahu, J. N., Sahoo, B. K., Mohanty, C. R., and Meikap B.C. (2009). Removal of Pb (II) from waste water by activated carbon developed from Tamarind wood activated zinc chloride, Chemical Engineering Journal, 149, 249-262.

[12] Goertzen, S. L., and Kim, D. (2010). The riault, Alicia M. Oickle Anthony C. Tarasuk Heather A. Andreas Standardization of the Boehm titration. Part I. CO2 expulsion and endpoint determination, Carbon, 48 $1252-1261$.

[13] Oickle, A. M., Sarah, L., Goertzen, L., Hopper, K. R., Abdalla, Y. O., and Heather A. A. (2010). Standardization of the Boehm titration, Part II, Method of agitation effect filtering and titrant Carbon 48, 3313-3322.

[14] Boehm, H. M. (2002). Surface Oxides and their Analysis - A critical Asssessment, Carbon, 40, 145-149.

[15] Naiyaa, T. K., Bhattacharya, A. K., Mandalb, S., and Das S. K. (2009). The sorption of lead (II) ions on rice husk ash, Journal of Hazardous Materials, 163, 1254-1264.

[16] Wang, F. Y., Wang, H., and Jian, W. M., Adsorption of Cd (II) ions from aqueous solution by a new low cost adsorbent-Bamboo charcoal, Journal of Hazardous Materials, 177, 300-306.

[17] Mobasherpoura, I., Salahi, E., Pazouki, K. M. (2010). Removal of Ni (II) from aqueous solutions by nanocrystalline calcium hydroxypatite, Journal of Saudi Chemical Society.

[18] Li, Y., Du, Q., Wang, X., Zhang, P., Wang, D., Wang, Z., and Xia, Y. (2010). Removal of lead from aqueous solution by activated carbon prepared from Enteromorpha prolifera by zinc chloride activation, Journal of Hazardous Materials, 183, 583-589.

[19] Chakravarty, A., Mohanty, A., Sudha, T. N., Upadhyaya, A.K, Konar J., Sirkar, J. K., Madhukar, A., and Gupta, K. K. (2010). Removal of $\mathrm{Pb}$ (II) ions from aqueous solutions by adsorption using bael leaves (Aege marmelos), Journal of Hazardous Materials, 173, 502-509. 